Introducción

\title{
Aceleración y modernidad: estructuras temporales, cambio social y crítica
}

\author{
Acceleration and Modernity: Temporal Structures, Social Change, and Critique
}

\section{Aceleração e modernidade: estruturas temporais, mudança social e crítica}

\section{Arthur Bueno * \\ * GOETHE-UNIVERSITÄT FRANKFURT}

Una serie de acontecimientos recientes pone el tema de la aceleración a la orden del día. La pandemia del Covid-19 es sin duda el caso más visible: con sus incertidumbres y su amenaza de catástrofe humanitaria, ha provocado una brusca interrupción de la normalidad capitalista, exigiéndonos un conjunto de nuevos esfuerzos científicos, medidas sanitarias y acciones de coordinación internacional, así como la reordenación de profundos aspectos de nuestras vidas. Si bien es cierto que la irrupción de la pandemia provocó, en algunos ámbitos y para ciertas partes de la población, una aceleración aún mayor del ritmo de vida, su resultado global fue al principio, como ha afirmado Hartmut Rosa, una "desaceleración forzada" de las dinámicas sociales imperantes ${ }^{1}$.

Sin embargo, desde el inicio de la pandemia hasta hoy hemos podido asistir a procesos de reaceleración de diversa índole. Aunque la velocidad de la vida capitalista ha sido puesta en jaque por la inesperada aparición de la crisis sanitaria, la expansión de los procesos de digitalización ha permitido mantener en movimiento un gran número de actividades económicas, a pesar de las restricciones a la circulación física. El perpetuum mobile de la aceleración capitalista vuelve a imponerse poco a poco, y con él la sensación -familiar para muchos de nosotros- de vivir en un estado de "paralización frenética"2. A su vez, también es gracias a la velocidad acelerada de nuestra sociedad que las soluciones a la pandemia, desde

\footnotetext{
${ }^{1}$ Hartmut Rosa, "La sociedad ante la desaceleración forzada: Una interpretación sociológica de la crisis del coronavirus", Diferencia(s): Revista de teoría social contemporánea 11 (2020): 19-32.

${ }^{2}$ La expresión deriva del título de la edición alemana (Rasender Stillstand) del libro de Paul Virilio L'Inertie polaire. Paul Virilio, La inercia polar (Madrid: Trama Editorial, 1999).
} 
el descubrimiento del funcionamiento del virus hasta la creación de nuevas vacunas, se han podido idear en un tiempo mucho menor que en ocasiones pasadas. Sin embargo, como se ha puesto de manifiesto en los últimos meses, la aplicación de estas soluciones está atravesada por enormes desigualdades que no sólo generan desastres humanitarios en diversas partes del mundo, sino que también socavan y retrasan la propia contención de la propagación del virus.

Operando una especie de reboot del mundo, la crisis sanitaria arroja nuevas luces sobre las dinámicas temporales de la sociedad capitalista, recordándonos hasta qué punto, para reproducirse como tal, esta no puede dejar de crecer a velocidad exponencial. En este contexto, las consecuencias contradictorias de la aceleración también se ponen de manifiesto: sus dinámicas producen un aumento constante de las posibilidades de control instrumental del mundo, pero sólo pueden hacerlo a través de una apropiación extremadamente desigual y destructiva de la actividad humana y de los recursos naturales. Así, si por un lado es gracias a la aceleración que la perspectiva de una contención de la pandemia se ha hecho posible, por el otro se debe igualmente a este proceso que dicha contención no haya ocurrido antes y se haga más difícil en la actualidad.

Las contradicciones inherentes a la aceleración no se manifiestan, por supuesto, sólo en la pandemia. Ya antes de ella, un conjunto de fenómenos sociales indicaba que estamos en medio de una crisis general del orden capitalista institucionalizado durante las últimas décadas $^{3}$. La creciente preocupación que suscita el problema del cambio climático coexiste con la ausencia generalizada de medidas adecuadas, a pesar de los pronósticos científicos de una catástrofe inminente. Los esfuerzos para cambiar la tendencia a una mayor acentuación de la desigualdad generada por el capitalismo financiarizado siguen siendo insuficientes, a pesar de la crisis económica de 2008 y de los pronósticos de otra por venir. El aumento de los diagnósticos de depresión y burnout -derivado de los imperativos de optimización y autenticidad personal, en un contexto marcado por la precarización- no ha sido suficientemente afrontado por políticas públicas que se centren en sus causas estructurales; por el contrario, lo que vemos es un aumento del trabajo precario y un previsible crecimiento del desempleo gracias a la automatización. Además, las instituciones políticas creadas en décadas de dominación neoliberal se han demostrado, en gran medida, incapaces de ampliar la

\footnotetext{
${ }^{3}$ Arthur Bueno, “¿Qué viene después de la depresión? Ocho tesis sobre la crisis de la subjetividad neoliberal y sus implicancias políticas”, Cuadernos de Teoría Social 6, no. 11 (2020): 95-120.
} 
participación democrática y de hacer frente a las presiones resultantes de las nuevas tecnologías digitales. No es de extrañar que, en este contexto, un número creciente de personas se sume a tendencias políticas autoritarias que prometen resolver estos problemas de un plumazo.

La crisis sanitaria de Covid-19 surgió, por tanto, en un mundo social ya en crisis. Tanto en la pandemia como en los otros fenómenos mencionados, el problema se presenta de forma similar: si la dinámica aceleradora del capitalismo en las últimas décadas promueve un aumento sin precedentes de la acumulación de recursos, es parte del mismo proceso que este enorme potencial tienda a ser utilizado, no tanto para aumentar el tiempo libre y contener las consecuencias destructivas de estos desarrollos, sino para impulsar aún más el círculo vicioso de la aceleración capitalista. Ahí radica una contradicción central de la vida moderna, a la que Marx -y tantos otros teóricos de la aceleración después de él, desde Simmel hasta Rosa- se refirió a través del concepto de alienación ${ }^{4}$. Es típico de las épocas de crisis, como la nuestra, que estas tensiones se radicalicen y manifiesten de forma más aguda. Por esto mismo, es también característico de estos momentos que surjan nuevas alternativas, para bien o para mal. La (múltiple) crisis de aceleración nos sitúa en una encrucijada histórica, marcada por la aparición de "síntomas mórbidos" 5 pero también por la apertura a otras formas posibles de organización social del tiempo.

Las contribuciones del presente número de Pléyade abordan estas cuestiones desde una gran variedad de puntos de vista. El dossier comienza con el artículo de Vera King, donde se ofrece un examen complejo de la experiencia psicosocial de la aceleración al distinguir, sobre la base de una investigación empírica cualitativa, diferentes estrategias adoptadas por los individuos para hacer frente a los imperativos sociales de autooptimización y a las tendencias a disolver las fronteras temporales entre el trabajo y la vida personal. Su análisis permite identificar en dichas estrategias tanto la promoción de una lógica instrumental en la relación consigo mismo y con los demás, como ciertos mecanismos de resistencia a tales imperativos.

\footnotetext{
4 Karl Marx, "Manuscritos Económico-Filosóficos de 1844", en Carlos Marx/Federico Engels. Obras Fundamentales. Marx escritos de juventud, tomo 1, W. Roces org., 557-668 (Ciudad de México: Fondo de Cultura Económica, 1982); Hartmut Rosa, Alienación y aceleración: hacia una teoría crítica de la temporalidad en la modernidad tardía (Buenos Aires: Katz Editores, 2016). Sobre el concepto de alienación en Simmel, véase: Arthur Bueno, "Rationality - Cultivation - Vitality: Simmel on the Pathologies of Modern Culture", Dissonância: Critical Theory Journal 2, no. 2 (2018): 96-135.

${ }^{5}$ Antonio Gramsci, Quaderni del Carcere. Vol. 1. (Torino: Einaudi, 1977), 311.
} 
En su contribución, Mauro Basaure se dedica a reconstruir los análisis de Hartmut Rosa sobre la aceleración en cuanto a las causas, la dimensión fenomenológica y la crítica de este proceso, destacando los rasgos distintivos de la teoría del autor en relación con otros estudios sociológicos sobre el tiempo. A través de un examen de los vínculos entre los análisis de Rosa sobre las consecuencias de la aceleración y la concepción de la resonancia articulada más recientemente por el sociólogo alemán, Basaure propone entender los aspectos alienantes de la aceleración como una "auto-tracción", es decir, una discrepancia entre las orientaciones de valor y las acciones reales. El artículo de Anders Petersen aborda la interrelación entre la aceleración y la crisis climática, argumentando que las dinámicas aceleradas de la sociedad contemporánea no sólo promueven los fenómenos problemáticos vinculados al cambio climático, sino que también crean obstáculos para una intervención colectiva eficaz sobre ellos. El texto también examina cómo la crisis climática produce formas específicas de sufrimiento psíquico y termina por proponer que el sentimiento de ira puede ser un vector de crítica y transformación de los problemas climáticos generados por la aceleración social.

El artículo de Celeste Viedma aborda las formas en que los escritos de ciertos pensadores latinoamericanos, como el chileno Carlos Matus y el argentino Oscar Varsavsky, presentan propuestas de "utopías viables" que se distinguen de los escenarios proyectados como tendencias naturales por la "futurología" de los tecnócratas. Revelando el futuro como algo a construir a partir de las decisiones y la imaginación política del presente, tales propuestas contribuyen a la crítica contemporánea en la medida en que se oponen a las tendencias a la inercia y a la destemporalización de la historia que acompañan paradójicamente a los procesos modernos de aceleración. En su contribución, Héctor Cataldo y Antoine Faure abordan las conexiones entre velocidad, información y poder. Basados en las tesis dromológicas de Paul Virilio, los autores conciben la información como un dispositivo de regulación rítmica del comportamiento y analizan sus implicaciones tanto para el periodismo como para las transformaciones actuales promovidas por el "internet de las cosas". Gustavo Bustos Gajardo aborda en su artículo el estado actual de las luchas de clase en Chile bajo condiciones neoliberales, así como sus potenciales devenires. Argumentando que el neoliberalismo promueve la precarización de la vida y genera mecanismos de control social a través de la autogestión individual, el autor considera la posibilidad de desarrollar un 
germen insurreccional a partir de protestas que permitan al individuo sensibilizarse con otra lectura de la realidad.

El dossier incluye también una entrevista de Darío Montero a Hartmut Rosa, en la que abordan la relación dialéctica entre el Estado nación y la lógica de la aceleración en la modernidad, así como la forma que ha tomado esta relación en tiempos recientes, marcados por el resurgimiento de los populismos nacionalistas. Además, abre la lectura del volumen una Intervención de mi autoría, que propone entender la pandemia de Covid-19 como una crisis dentro de otra crisis: la del orden social instituido en el último cuarto del siglo XX y su correspondiente forma de subjetividad. Si la irrupción de la pandemia apareció inicialmente como una desaceleración forzada, las diversas reacciones que la siguieron pueden también entenderse en términos de diferentes experiencias temporales: "desaceleración inmersiva", “desaceleración angustiada", "reaceleración exasperada” y “desaceleración planificada”. 


\section{Referencias bibliográficas}

Bueno, Arthur. “¿Qué viene después de la depresión? Ocho tesis sobre la crisis de la subjetividad neoliberal y sus implicancias políticas”. Cuadernos de Teoría Social 6, no. 11 (2020): 95-120.

-----. "Rationality - Cultivation - Vitality: Simmel on the Pathologies of Modern Culture". Dissonância: Critical Theory Journal 2, no. 2 (2018): 96-135.

Gramsci, Antonio. Quaderni del Carcere. Vol. 1. Torino: Einaudi, 1977.

Marx, Karl. "Manuscritos Económico-Filosóficos de 1844”. En Carlos Marx/Federico Engels. Obras Fundamentales. Marx escritos de juventud, tomo 1, Wenceslao Roces organizador, 557-668. Ciudad de México: Fondo de Cultura Económica, 1982.

Rosa, Hartmut. Alienación y aceleración: hacia una teoría crítica de la temporalidad en la modernidad tardía. Buenos Aires: Katz Editores, 2016.

-----. "La sociedad ante la desaceleración forzada: Una interpretación sociológica de la crisis del coronavirus", Diferencia(s): Revista de teoría social contemporánea 11 (2020): 19-32.

Virilio, Paul. La inercia polar. Madrid: Trama Editorial, 1999.

\section{Sobre el autor}

Arthur Bueno. Profesor asistente en el Departamento de Filosofía de la Goethe-Universität Frankfurt am Main (Fráncfort del Meno, Alemania). Profesor visitante en el Instituto de Psicología de la Universidad de São Paulo. Investigador del centro de investigación Normative Orders (Goethe-Universität, Fráncfort del Meno) y del Núcleo Direito e Democracia (CEBRAP, São Paulo). Fue becario postdoctoral de la Fundación Alexander von Humboldt en el Max-Weber-Kolleg de la Universidad de Erfurt y en la Universidad de París-Nanterre. Es autor de Economies of Life: Simmel on Money and Art (Londres: Routledge, en prensa) y editor de Critical Theory and New Materialisms, con Hartmut Rosa y Christoph Henning (Londres: Routledge, 2021), De-centering Social Theory and Research: The Peripheral Turn in Sociology, con Mariana Teixeira y David Strecker (Londres: Routledge, en prensa), y O conflito da cultura moderna e outros escritos: Georg Simmel (São Paulo: Senac, 2013), así como de varios números especiales en revistas académicas. Sus 
investigaciones se centran en la teoría crítica, la teoría social, las formas de subjetividad y el sufrimiento psíquico. Correo electrónico: oliveira@normativeorders.net. 